WHOI-89-56

\title{
Report on Sediment TRansport Events on Shelf and Slope (STRESS) Field Season 1: Winter 1988-1989 Benthic Acoustic Stress Sensor (BASS) Component
}

by

Ellyn T. Montgomery, C.V.R. Dunn, A.J. Williams 3rd

Woods Hole Oceanographic Institution

Woods Hole, Massachusetts 02543

December 1989

Technical Report

Funding was provided by the Office of Naval Research under Contract No. N000-14-89-J-1058

Reproduction in whole or in part is permitted for any purpose of the

United States Government. This report should be cited as:

Woods Hole Oceanog. Inst. Tech. Rept., WHOI-89-56.

Approved for publication; distribution unlimited.

Approved for Distribution:

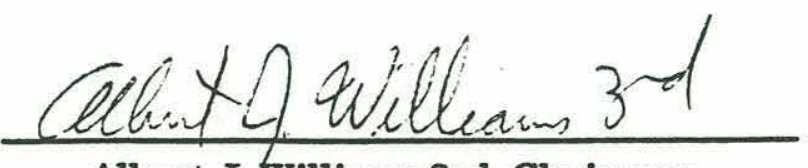

Albert JoWilliams 3rd, Chairman

Department of Applied Ocean Physics and Engineering 


\section{Contents}

List of Figures $\quad$ ii

List of Tables $\quad$ ii

Abstract $\quad$ iii

1 Introduction 1

2 STRESS BASS Description 6

2.1 Instrumentation . . . . . . . . . . . . . . . . . 6

2.2 Data Format . . . . . . . . . . . . . . . . . 10

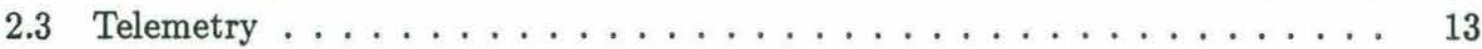

3 Preliminary Results $\quad 18$

4 Cruise Reports $\quad 20$

4.1 Deployment Cruise Report For R/V WECOMA - Nov. 27-30, 1988 . . . . . . 20

4.1 .1 SMILE Leg $3 /$ STRESS $\operatorname{Leg} 1 \ldots \ldots \ldots . \ldots \ldots$

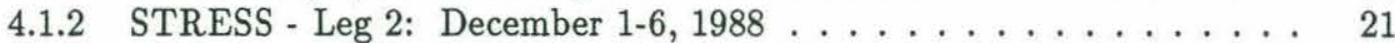

4.1.3 STRESS - Leg 3: December 7-9, $1988 \ldots \ldots \ldots \ldots 22$

4.2 Turn-Around Cruise Report . . . . . . . . . . . . . . . . . . 25

4.2 .1 Scientific Objective . . . . . . . . . . . . . . 25

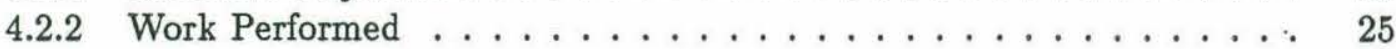

4.3 Recovery Cruise Report . . . . . . . . . . . . . . . . . . . 29

4.3.1 Leg 1: March 12-14,1989 . . . . . . . . . . . . . . . . 29

4.3.2 Leg 2: March 17-19, $1989 \ldots \ldots \ldots \ldots \ldots \ldots$

4.3 .3 Leg 3: March 21-23, $1989 \ldots \ldots \ldots \ldots \ldots \ldots$

5 Acknowledgements $\quad 31$

6 References $\quad 31$ 


\section{List of Figures}

1 Chart showing the experimental area, SMILE mooring locations and STRESS site (near $\mathrm{C} 3$ mooring). . . . . . . . . . . . . . . . . . . . 2

2 Expanded scale chart showing STRESS tripod deployment positions . . . . . 4

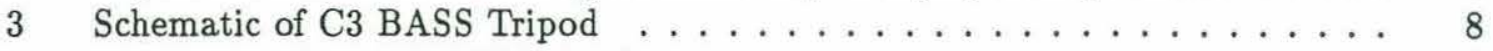

4 Schematic of LDV BASS Tripod . . . . . . . . . . . . . . . 9

5 Schematic of Command and Data Transmission Paths . . . . . . . . . 15

6 Telemetry Buoy Configuration . . . . . . . . . . . . . . . . 16

7 Telemetry Buoy and Tripod Deployment Configuration . . . . . . . . . . 17

8 Time Series of Uncorrected Temperature and Transmision Data from the C3 BASS Tripod. . . . . . . . . . . . . . . . . . . . . . . 19

\section{List of Tables}

1 Tripod Instrumentation and Deployment Summary . . . . . . . . . . . 3

2 BASS and LDV Tripod Sensor Heights . . . . . . . . . . . . . . 7

3 BASS Averaged Record Data Format . . . . . . . . . . . . . . . . 11

4 BASS Tattletale Spectra Record Data Format . . . . . . . . . . . . . . 12

5 BASS Event Record Data Format . . . . . . . . . . . . . . . . . . 12 


\begin{abstract}
Data on the effects of winter conditions on the transport of sediment on the continental shelf off Northern California were collected during the first year of the Sediment TRansport Events on Shelves and Slopes (STRESS) Experiment. This experiment was done in conjunction with (Shelf MIxed Layer Experiment) SMILE and (Biological Effects on Coastal Ocean Sediment Transport) BECOST to provide a complete suite of measurements of nearshore dynamics, sediment transport, and biological interactions.

This report includes a general description of the work accomplished during the first STRESS field season, carried out in the winter of 1988-1989 off the Northern California coast. Three cruises were completed during the STRESS experiment, one each for deployment, turnaround, and recovery of the instruments. This created two back-to-back sections of data, one from December 4, 1988 to January 23, 1989, and the other from January 29 to March 17, 1989.

This report also documents in detail the use of the Benthic Acoustic Stress Sensor (BASS), and the associated acoustic data telemetry link in STRESS. BASS has been used in different configurations previously, but the acoustic telemetry system is new.
\end{abstract}




\section{Introduction}

The Sediment TRansport Events on Shelves and Slopes (STRESS) field program (Year 1) occurred off the coast of Northern California during the winter of 1988-1989. The overall objective of the STRESS project is to increase our understanding of sediment transport on the shelf under the influence of winter storms. Silt carried down from the Russian River forms a band of sediment at 90 meters that extends northward along the coast toward but not reaching Pt. Arena. It is probable that the winter conditions of large swell and strong wind driven currents are responsible for most of the sediment transport. Strong bottom stress from the waves erodes and suspends sediment which is then carried by the current. The purpose of STRESS is to observe these events, measuring the stress, waves, currents, suspended sediments, and such gradients in these quantities that we can.

The work done in STRESS was part of a larger effort to describe winter coastal oceanographic processes, which included Shelf MLxed Layer Experiment (SMILE), and Biological Effects of Coastal Ocean Sediment Transport (BECOST). The STRESS work concentrated primarily on the bottom and near bottom dynamics, SMILE studies covered surface and midwater dynamics and atmospheric forcing, and BECOST investigations centered on benthic organisms and bioturbation. Figure 1 shows the area where this research was conducted. The labels C2, C3, C4, G3 and M3 denote SMILE mooring locations; the "C-line" was across shelf, and the "3-line" was along shelf on the $90 \mathrm{~m}$ isobath.

The primary goal of the STRESS field program was to collect data that could explain how winter storms effect sediment transport on the shelf. To this end, an array of tripods was deployed in 90 meters of water near the SMILE Central (C3) mooring. The instrumentation and investigator responsible for each tripod and the deployment dates and locations are listed in Table 1. Figure 2 shows where the STRESS tripods, moorings, and guard buoys were placed with respect to the SMILE C3 mooring. The SMILE C3 surface mooring with meteorological sensors and a United States Geological Survey (USGS) subsurface mooring provided complementary measurements. The data obtained from all these instruments should provide new insight on the processes involved in mixing and sediment transport on the shelf.

Another important component of STRESS was data telemetry. Along with being logged internally, the data from BASS could be transmitted to the surface using a 1200 baud acoustic path at $30 \mathrm{kHz}$, received by a surface buoy, and then sent to shore using radio transmissions. A Tattletale computer was incorporated into the BASS to control the internal logging and telemetry functions. The Tattletale also computed Fast Fourier Transforms (FFT's) and averages of the data it received. A receiving station was established on shore to acquire and log the data transmitted from the buoy. The person at the receiving station could control the acquisition of high frequency data to correspond with periods of heavy seas and/or high winds.

The STRESS field program was carried out in two parts to allow intermediate data recovery and re-batterying of the tripods. The instruments were deployed from the R/V WECOMA between December 1 and 6, 1988, they were serviced from the R/V PT. SUR January 23 to 29, 1989, and were finally recovered on the R/V WECOMA between March 16 and 23, 1989. 


\section{STRESS/SMILE LOCATION}

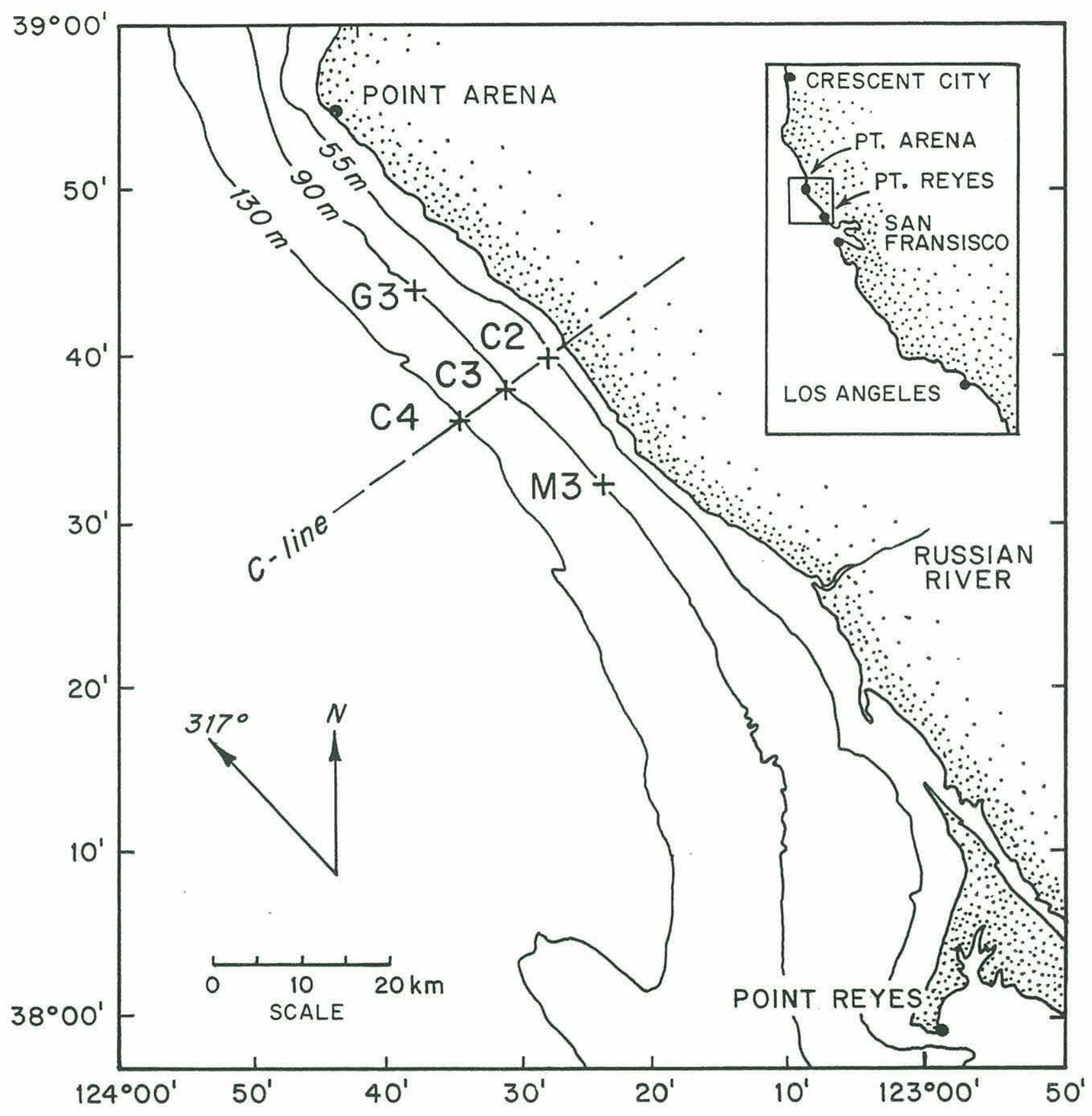

Figure 1: Chart showing the experimental area, SMILE mooring locations and STRESS site (near C3 mooring). 
Table 1: Tripod Instrumentation and Deployment Summary

BASS Tripod (90 meters) - A.J. Williams 3rd (WHOI):

BASS (Benthic Acoustic Stress Sensor) - Bayshore IV

( 6 acoustic current meters, 8 thermistors, 2 transmissometers, pressure, compass)

LDV tripod (50 meters) - Y. Agrawal (Flow Res.):

First STRESS deployment - Laser Doppler Velocimeter only.

Second STRESS deployment - LDV and BASS (4 acoustic current meters, 3 thermistors,

2 transmissometers, pressure, and compass) - Bayshore III - A. J. Williams 3rd (WHOI)

SS Tripod (90 meters) - D. Jackson (Univ. WA):

Scanning Sonar

FVSK Tripod (90 meters) - A. Nowell (Univ. WA):

Free Vehicle Stereo Camera

ABSS Tripod (90 meters) - J. Lynch (WHOI):

Acoustic BackScatter Sensor

(upward looking $1 \mathrm{MHz}$ system, and downward looking $5 \mathrm{MHz}$ system)

LISST (LIght Scattering and Settling Tube) - Y. Agrawal (Flow Res.)

OBS (Optical Backscattering System) - R. Sternberg (Univ. WA)

Suspended Sediment Sampler

ROST (Remote Optical Settling Tube) - R. Bartz (Sea Tech.)

Deployment Dates and Locations

(all times are Pacific Standard Time)

Tripod Date Deployed Date Recovered

Position

\begin{tabular}{cccc} 
BASS & $11 / 28 / 881130$ & $01 / 25 / 891440$ & $38^{\circ} 38.51^{\prime} \mathrm{N} 123^{\circ} 29.47^{\prime} \mathrm{W}$ \\
& $01 / 26 / 891239$ & $03 / 18 / 890730$ & $38^{\circ} 38.48^{\prime} \mathrm{N} 123^{\circ} 29.67^{\prime} \mathrm{W}$ \\
LDV & $12 / 08 / 880853$ & $01 / 24 / 891700$ & $38^{\circ} 37.34^{\prime} \mathrm{N} 123^{\circ} 23.51^{\prime} \mathrm{W}$ \\
& $01 / 25 / 891330$ & $03 / 17 / 891400$ & $38^{\circ} 37.35^{\prime} \mathrm{N} 123^{\circ} 23.48^{\prime} \mathrm{W}$ \\
SS & $12 / 03 / 880934$ & $01 / 28 / 891028$ & $38^{\circ} 38.58^{\prime} \mathrm{N} 123^{\circ} 29.29^{\prime} \mathrm{W}$ \\
& $0128 / 880130$ & $03 / 14 / 891345$ & $38^{\circ} 38.58^{\prime} \mathrm{N} 123^{\circ} 29.51^{\prime} \mathrm{W}$ \\
ABSS & $12 / 04 / 881433$ & $12 / 09 / 881045$ & $38^{\circ} 38.79^{\prime} \mathrm{N} 123^{\circ} 29.44^{\prime} \mathrm{W}$ \\
\multicolumn{3}{c}{ (The acoustic release pre-released almost immediately after deployment, so ABSS was } \\
\multicolumn{4}{c}{ recovered and redeployed.) }
\end{tabular}

ABSS $12 / 09 / 881342 \quad 03 / 21 / 891230 \quad 38^{\circ} 38.70^{\prime} \mathrm{N} 123^{\circ} 29.53^{\prime} \mathrm{W}$

(The floats of the recovery system did not come to the surface when released, so the ABSS tripod could not be recovered as planned on the turn-around cruise.)

FVSK $\quad 01 / 24 / 891028 \quad 03 / 14 / 891530 \quad 38^{\circ} 38.70^{\prime} \mathrm{N} 123^{\circ} 29.27^{\prime} \mathrm{W}$

(The FVSK tripod was not deployed during the first half of STRESS.) 


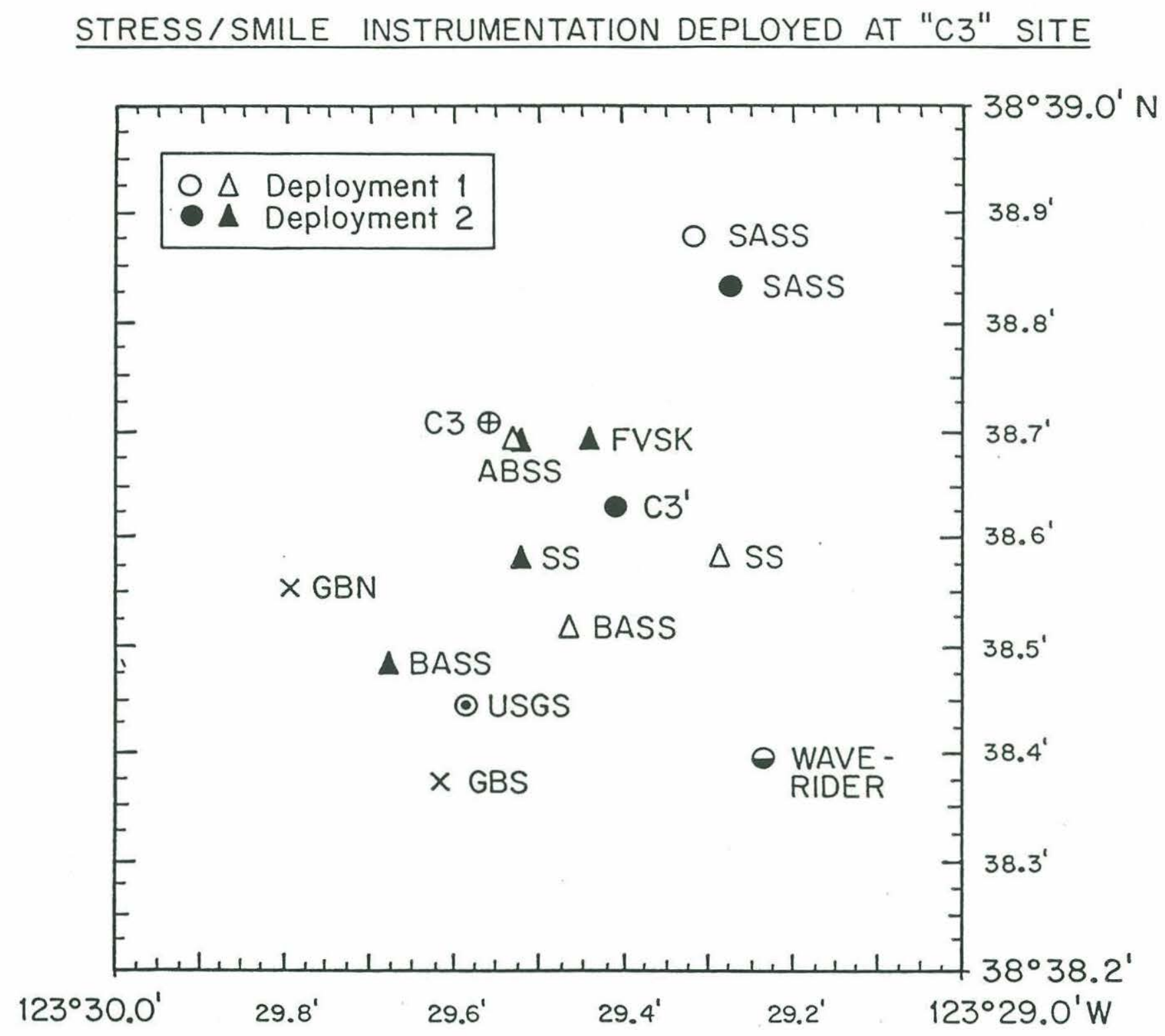

Figure 2: Expanded scale chart showing STRESS tripod deployment positions 
The staging for the first and third cruises was done at athe Army Corps of Engineers' Bay Model Visitor Center in Sausalito, California, and the second cruise was staged from the marine lab facility in Moss Landing, CA.

This report will document the BASS work and telemetry aspects of STRESS, and describe the work done on each of the cruises. The other components of the STRESS program will be documented elsewhere. The report has three parts: a description of BASS and the telemetry link as used in this experiment, a discussion of some preliminary results, and a log of the activities of each of the three cruises. 


\section{STRESS BASS Description}

Two BASSes were deployed during STRESS. One was deployed near the SMILE C3 mooring in 90 meters of water, and had acoustic telemetry capabilities. The second was deployed for the second half of the experiment in 50 meters of water on the LDV tripod. The instruments will be referred to as the C3 and LDV BASSes respectively. The mooring positions of these tripods during STRESS are shown in Figure 2.

In addition to the standard suite of BASS measurements, in these deployments, an Onset Computers Tattletale IV was used to control logging and telemetry of the data, and to compute and store velocity and pressure spectra. During the second half of the experiment three thirty- minute records of unaveraged high frequency data were stored in the Tattletales and retrieved from memory after recovery.

The BASS tripods used in STRESS had a dual burn wire release holding a float which carried a $\frac{1}{2}$ inch Dacron line to the surface on command (Dunn and Gordon, in preparation). This allowed the whole tripod to be recovered, as opposed to the usual deep sea method where the base is left on the bottom. In this near shore environment, tripod bases abandoned on the bottom would provide too great a hazard to trawlers and other fishermen. The line was 140 meters long and was coiled in a crate on the tripod's four meter platform. It was secured with $10 \mathrm{lb}$ test monofilament line. The run from the crate to the float was enclosed in split garden hose to shield it from wave action but permit easy deployment when released. An acoustic command receiver (ACR) was the principal release mode. The backup release was a Timer/Pinger. If the ACR does not detect a release command and misses its programmed release time, the timer attempts to release at a later programmed date.

The other new development during STRESS was the use of acoustic telemetry to send the data from the tripod to a moored transmission buoy which relayed the data ashore. The telemetry allowed more high frequency data to be recovered than could be internally recorded on the Sea Data cassettes.

\subsection{Instrumentation}

The C3 BASS tripod, as deployed in STRESS, measured velocity at six heights, from $20 \mathrm{~cm}$ to 5 meters, every $150 \mathrm{~ms}$ to determine Reynolds stress and turbulent kinetic energy responsible for sediment transport under waves. Averages of velocity and velocity correlations were formed over 30 minutes and recorded on Sea Data cassettes. In addition, temperature at eight heights and optical transmission at two heights were measured every 10 minutes and recorded along with the 30 minute means. Pitch and roll were included in these records to determine tripod attitude. Though the compass was not logged to cassette, it was included in the telemetered data on the C3 BASS and was stored by the Tattletales on both BASS tripods during the second half of the experiment.

The BASS mounted on the LDV tripod measured velocity with four acoustic current meters, between $20 \mathrm{~cm}$ and 5 meters above the bottom. Three thermistors provided temperature measurements. Two transmissometers, pitch, roll and compass completed the instrumentation 
package. The sample intervals, averaging periods, and logging to cassette were the same as for the C3 BASS. The LDV BASS did not have any capability for telemetry. The instrument assignments and locations are summarized in Table 2.

Table 2: BASS and LDV Tripod Sensor Heights

\begin{tabular}{|c|c|c|c|c|}
\hline Sensor & $\begin{array}{l}\text { C3 BASS } \\
\text { height above deck }\end{array}$ & Est. HAB & $\begin{array}{c}\text { LDV BASS } \\
\text { height above deck }\end{array}$ & Est. HAB. \\
\hline $\mathrm{ACM} 1$ & $17-28.5 \mathrm{~cm}$ & $20 \mathrm{~cm}$ & $36-47 \mathrm{~cm}$ & $39 \mathrm{~cm}$ \\
\hline $\mathrm{ACM} 2$ & $47-58.5 \mathrm{~cm}$ & $50 \mathrm{~cm}$ & $71-82 \mathrm{~cm}$ & $74 \mathrm{~cm}$ \\
\hline ACM 3 & $107.5-119 \mathrm{~cm}$ & $111 \mathrm{~cm}$ & $106-117 \mathrm{~cm}$ & $109 \mathrm{~cm}$ \\
\hline $\mathrm{ACM} 4$ & $193-204.5 \mathrm{~cm}$ & $196 \mathrm{~cm}$ & $499-510 \mathrm{~cm}$ & $502 \mathrm{~cm}$ \\
\hline $\mathrm{ACM} 5$ & $253-264.5 \mathrm{~cm}$ & $256 \mathrm{~cm}$ & not used & $\ldots$ \\
\hline $\mathrm{ACM} 6$ & $493-504.5 \mathrm{~cm}$ & $496 \mathrm{~cm}$ & not used & $\cdots$ \\
\hline Therm 1 & $40 \mathrm{~cm}$ & $37 \mathrm{~cm}$ & $41.5 \mathrm{~cm}$ & $39 \mathrm{~cm}$ \\
\hline Therm 2 & $65 \mathrm{~cm}$ & $62 \mathrm{~cm}$ & $111.5 \mathrm{~cm}$ & $109 \mathrm{~cm}$ \\
\hline Therm 3 & $113 \mathrm{~cm}$ & $110 \mathrm{~cm}$ & $504.5 \mathrm{~cm}$ & $502 \mathrm{~cm}$ \\
\hline Therm 4 & $204 \mathrm{~cm}$ & $201 \mathrm{~cm}$ & not used & $\ldots$ \\
\hline Therm 5 & $254 \mathrm{~cm}$ & $251 \mathrm{~cm}$ & not used & $\ldots$ \\
\hline Therm 6 & $365 \mathrm{~cm}$ & $363 \mathrm{~cm}$ & not used & $\cdots$ \\
\hline Therm 7 & $502 \mathrm{~cm}$ & $500 \mathrm{~cm}$ & not used & $\ldots$ \\
\hline Therm 8 & $586 \mathrm{~cm}$ & $584 \mathrm{~cm}$ & not used & $\cdots$ \\
\hline Trans 1 & $43-48 \mathrm{~cm}$ & $43 \mathrm{~cm}$ & $38-62 \mathrm{~cm}$ & $48 \mathrm{~cm}$ \\
\hline Trans 2 & $144 \mathrm{~cm}$ & $141 \mathrm{~cm}$ & $148 \mathrm{~cm}$ & $146 \mathrm{~cm}$ \\
\hline Pressure & $360 \mathrm{~cm}$ & $358 \mathrm{~cm}$ & not used & $\cdots$ \\
\hline Camera & $324 \mathrm{~cm}$ & $321 \mathrm{~cm}$ & not used & $\cdots$ \\
\hline Strobe & $80 \mathrm{~cm}$ & $77 \mathrm{~cm}$ & not used & $\cdots$ \\
\hline
\end{tabular}

Key:

$\mathrm{ACM}=$ Acoustic current meter, pod \#

Therm $=$ Thermistor

Trans $=$ Transmissometer

$\mathrm{HAB}=$ Height above deck

Figure 3 shows a schematic of the C3 BASS tripod, while Figure 4 shows a schematic of the LDV BASS tripod. 


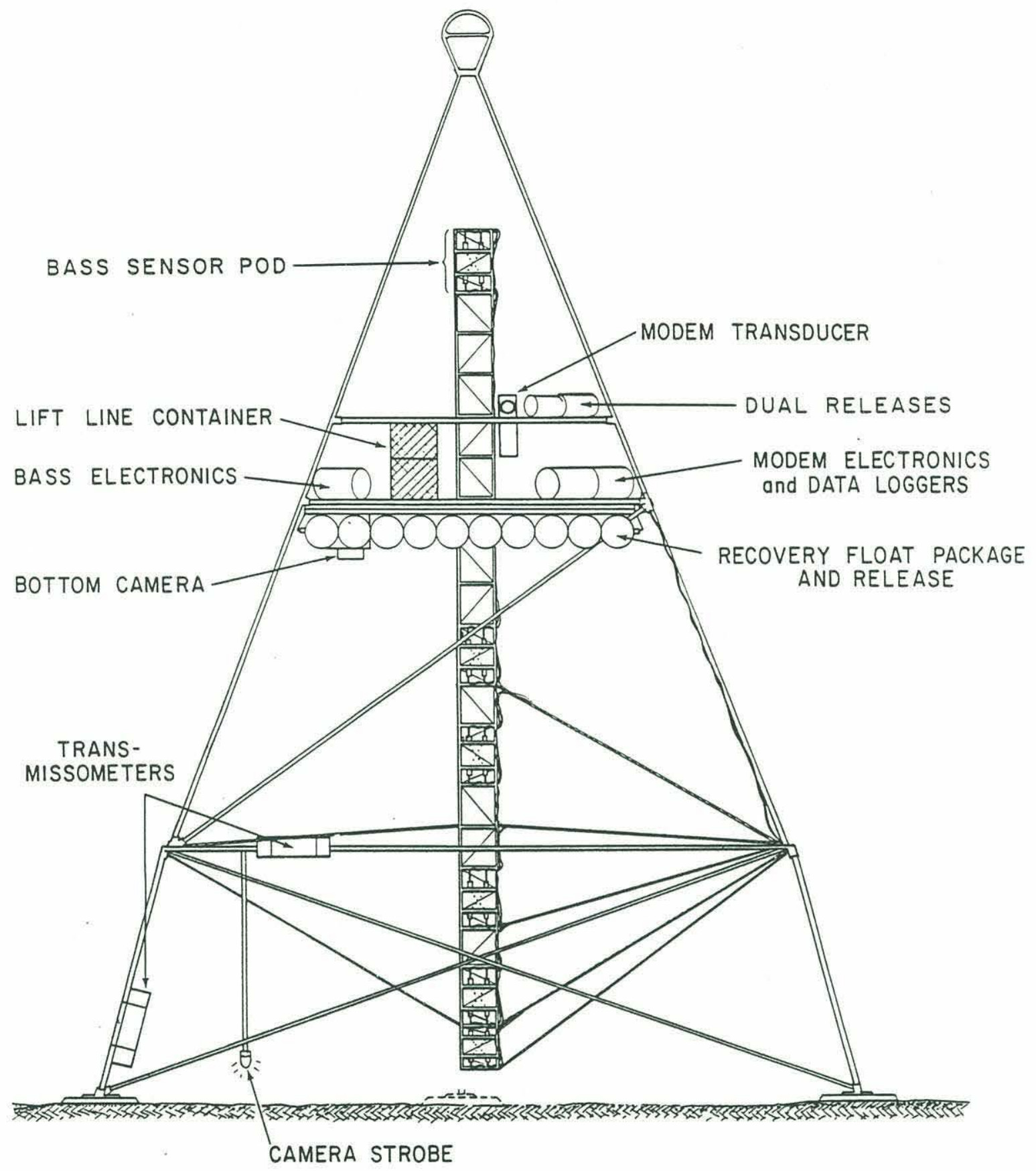

C3 BASS TRIPOD

Figure 3: Schematic of C3 BASS Tripod 


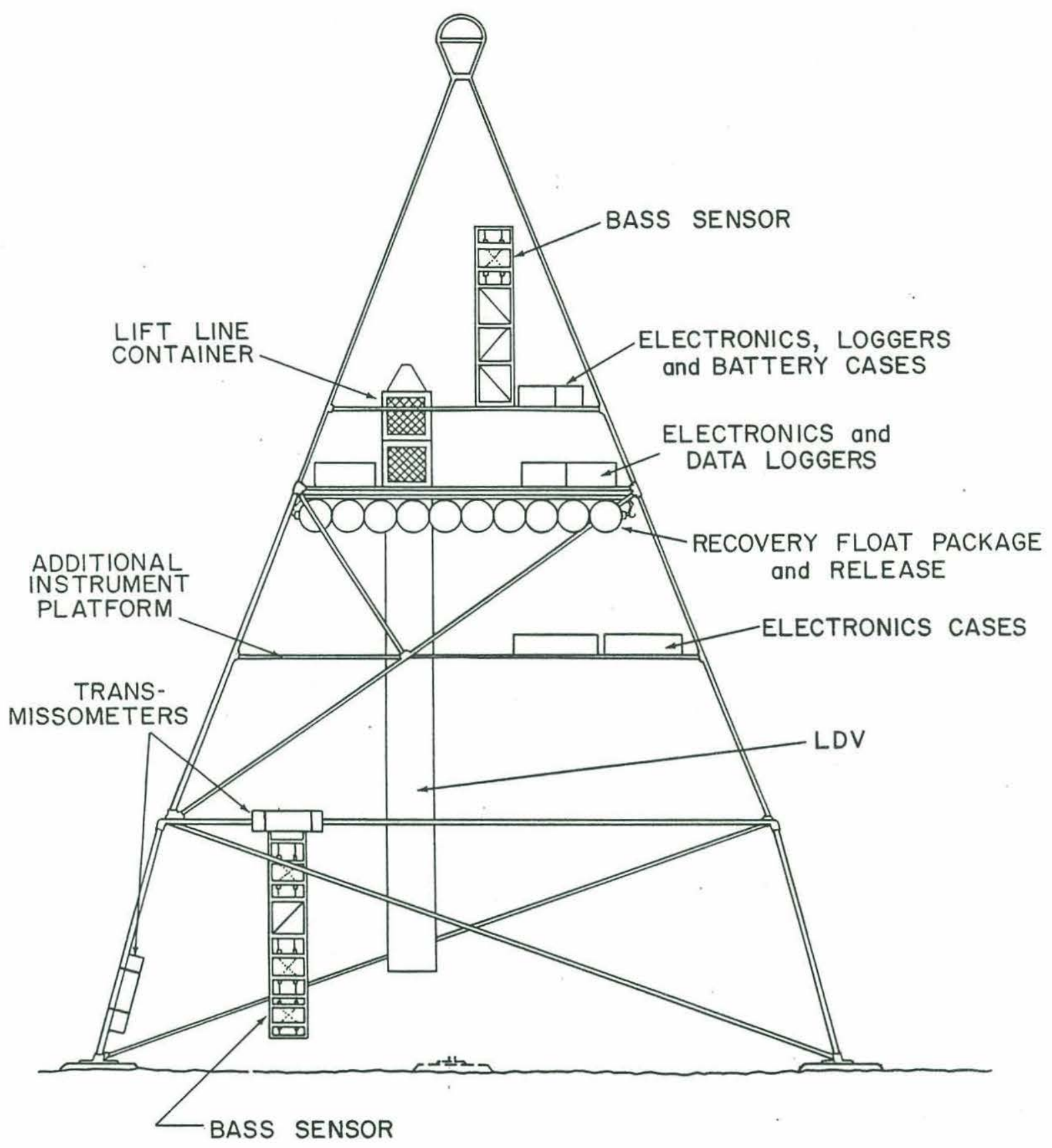

Figure 4: Schematic of LDV BASS Tripod 


\subsection{Data Format}

Every half hour three data records were written to the Sea Data cassette tape and also transmitted acoustically. The first of the three contained the BASS current meter averages. The two records following the BASS averages on the Sea Data cassettes contain the spectra computed by the Tattletale, and have the same length as the BASS average records. During the time the averages were being accumulated, the velocity components and pressure were passed to the Tattletale IV every $600 \mathrm{~ms}$ for further processing. The velocity components were averages of four successive measurements but the pressure was a spot value measured with a Paroscientific Digiquartz transducer. These measurements were accumulated for 25.6 minutes then FFTs were computed for pressure, $u$ and $v$ velocity from the 1 meter sensor, and vertical velocity from the sensors at $50 \mathrm{~cm}, 1$ meter, 2 meters, and 2.5 meters. The format of logged records two and three is the same. The data format of the BASS average record is shown in Table 3, and the format of the spectra records is shown in Table 4.

Upon command, event records identical to those sent to the Tattletale, are transmitted by acoustic modem. Command 1 results in 25.6 minutes of event record transmission at 1200 baud starting at the next hour after the command is received. Command 2 repeats the 25.6 minute transmission seven more times on successive hours. The record rate is $1.67 \mathrm{~Hz}$ and consists of averages of four measurements for each record. The format of the event record shown in Table 5.

All BASS data are binary integers. The scaling of velocity is $1.875 \mathrm{E}-3 \mathrm{~cm} / \mathrm{s}$ per bit with an offset of approximately 8000 hex for zero velocity. The zeros were determined by a bagged deployment off the dock in Sausalito before the cruise. When the values for each axis obtained from that deployment are subtracted, the resulting signed integer is the velocity component along the axis, positive when flow is toward the transducer on the upper ring. Each velocity word is two bytes for a full scale range of plus or minus $61.44 \mathrm{~cm} / \mathrm{s}$ along the axis.

The sensor geometry defines four axes, each $15 \mathrm{~cm}$ long, along which the velocity components are measured. Each is inclined $45^{\circ}$ to the horizontal and spaced $90^{\circ}$ in azimuth rotated clockwise looking down starting with the A axis in the direction of the BASS compass lubberline. Thus V11 is the velocity component along the A axis of the lowest sensor, positive for flow toward the upper A transducer, V12 is the velocity component along the B axis of the lowest sensor which is $90^{\circ}$ right looking down, etc. For additional information on BASS, refer to Williams, et al., 1987.

In general, $u, v$, and $w$ are defined as the downstream, cross-stream, and vertical components of the flow. These directions are defined over any particular averaging time by the requirement that $w$ be vertical to the pitch and roll measurements, $v$ be perpendicular to $w$ but have zero mean, and $u$ be perpendicular to $v$ and $w$. In the data formats however, $u, v$, and $w$ sometimes appear without indices. This is a way to separate horizontal and vertical components with little in situ computation. For these purposes, $u$ is defined as (A-C)*.707, $v$ is (B- D)*.707, and $w$ is $(\mathrm{A}+\mathrm{B}+\mathrm{C}+\mathrm{D})^{*} .354$. These are used in the FFTs. For the two minute averages of $\mathrm{U}$ and $\mathrm{V}, 800$ measurements of $\mathrm{A}-\mathrm{C}$ and $\mathrm{B}-\mathrm{D}$ are accumulated, shifted 12 bits 
Table 3: BASS Averaged Record Data Format

\begin{tabular}{|c|c|c|c|c|}
\hline \\
\hline \multicolumn{5}{|c|}{$\begin{array}{llll}\text { AA } & \text { FO } & & \\
\text { MO } & \text { DA } & \text { HR } & \text { MN }\end{array}$} \\
\hline \multicolumn{2}{|c|}{ V11- V12- V13- } & \multicolumn{3}{|l|}{ V14- } \\
\hline V21- V2 & 2- V23- & V24- & & \\
\hline 31- V3 & 2- V33- & V34- & & \\
\hline V41- V4 & 2- V43- & V44- & & \\
\hline $51-\quad$ V5 & 2- V53- & V54- & & \\
\hline $61-\quad$ V6 & 2- V63- & V64- & & \\
\hline Q1 Q2 & Q3 Q4 & Q5 Q6 & & \\
\hline $\mathrm{A} 2 * \mathrm{~A} 2$ & $\mathrm{~A} 2 * \mathrm{~B} 2$ & $\mathrm{~A} 2 * \mathrm{C} 2$ & $\mathrm{~A} 2 * \mathrm{D} 2$ & $\mathrm{~B} 2 * \mathrm{~B} 2$ \\
\hline $\mathrm{B} 2 * \mathrm{C} 2$ & $\mathrm{~B} 2 * \mathrm{D} 2$ & $\mathrm{C} 2 * \mathrm{C} 2$ & $\mathrm{C} 2 * \mathrm{D} 2$ & $\mathrm{D} 2 * \mathrm{D} 2$ \\
\hline $\mathrm{A} 3 * \mathrm{~A} 3$ & $\mathrm{~A} 3{ }^{*} \mathrm{~B} 3$ & $\mathrm{~A} 3 * \mathrm{C} 3$ & $\mathrm{~A} 3 * \mathrm{D} 3$ & $\mathrm{~B} 3{ }^{*} \mathrm{~B} 3$ \\
\hline $\mathrm{B} 3{ }^{*} \mathrm{C} 3$ & $\mathrm{~B} 3 * \mathrm{D} 3$ & $\mathrm{C} 3 * \mathrm{C} 3$ & $\mathrm{C} 3 * \mathrm{D} 3$ & D3*D3 \\
\hline $\mathrm{A} 4 * \mathrm{~A} 4$ & $\mathrm{~A} 4 * \mathrm{~B} 4$ & $\mathrm{~A} 4 * \mathrm{C} 4$ & $\mathrm{~A} 4 * \mathrm{D} 4$ & $\mathrm{~B} 4 * \mathrm{~B} 4$ \\
\hline $\mathrm{B} 4 * \mathrm{C} 4$ & $\mathrm{~B} 4 * \mathrm{D} 4$ & $\mathrm{C} 4{ }^{*} \mathrm{C} 4$ & $\mathrm{C} 4 * \mathrm{D} 4$ & $\mathrm{D} 4 * \mathrm{D} 4$ \\
\hline $\mathrm{A} 5 * \mathrm{~A} 5$ & $\mathrm{~A} 5 * \mathrm{~B} 5$ & $\mathrm{~A} 5 * \mathrm{C} 5$ & $\mathrm{~A} 5 * \mathrm{D} 5$ & $\mathrm{~B} 5 * \mathrm{~B} 5$ \\
\hline $\mathrm{B} 5 * \mathrm{C} 5$ & $\mathrm{~B} 5 * \mathrm{D} 5$ & $\mathrm{C} 5{ }^{*} \mathrm{C} 5$ & C5*D5 & D5*D5 \\
\hline U3 V3 & U3 V3 & U3 V3 & U3 V3 & U3 V3 \\
\hline U3 V3 & U3 V3 & U3 V3 & U3 V3 & U3 V3 \\
\hline U3 V3 & U3 V3 & U3 V3 & U3 V3 & U3 V3 \\
\hline
\end{tabular}

T1- - T2- - T3- - T4- - T5 - . T6- .

T7- - T8- - TR1- TR2- PTCH ROLL

T1- - T2- - T3- - T4 - T5- - T6- -

T7- - T8- - TR1- TR2- PTCH ROLL

T1- - T2- - T3- - T4- - T5- - T6- -

T7- - T8- - TR1- TR2- PTCH ROLL
Header, keyword and length, 242 bytes ASCII date and time Velocity component means

Quality words, 2 bits/axis Reynolds stress products, sensors $2,3,4$, and 5 .

Two minute means of horizontal velocity, middle 8 bits of word.

Analog measurements

0 minutes / 30 minutes

10 minutes / 40 minutes

20 minutes / 50 minutes 
Table 4: BASS Tattletale Spectra Record Data Format

$\begin{array}{lllllllll}\text { AA F0 } & \text { 09 30 } & & & & & & & \text { HEADER INFORMATION } \\ \text { LF01 } & \text { LF02 } & \text { LF03 } & \text { LF04 } & \text { LF05 } & \text { LF06 } & \text { LF07 } & \text { LF08 } & \\ \text { LF09 } & \text { LF10 } & \text { LF11 } & \text { LF12 } & \text { LF13 } & \text { LF14 } & \text { LF15 } & \text { LF16 } & \\ \text { LF17 } & \text { LF18 } & \text { LF19 } & \text { LF20 } & \text { LF21 } & \text { LF22 } & \text { LF23 } & \text { LF24 } & \text { low FFT 1 } \\ \text { LF25 } & \text { LF26 } & \text { FL27 } & \text { LF28 } & \text { LF29 } & \text { LF30 } & \text { LF31 } & \text { LF32 } & \text { pressure / V pod 3 } \\ \text { LF33 } & \text { LF34 } & \text { LF35 } & \text { LF36 } & \text { LF37 } & \text { LF38 } & \text { LF39 } & \text { LF40 } & \\ \text { LF41 } & \text { LF42 } & \text { LF43 } & \text { LF44 } & \text { LF45 } & \text { LF46 } & & & \\ \text { LF01 } & \text { LF02 } & \text { LF03 } & \text { LF04 } & \text { LF05 } & \text { LF06 } & \text { LF07 } & \text { LF08 } & \\ \text { LF09 } & \text { LF10 } & \text { LF11 } & \text { LF12 } & \text { LF13 } & \text { LF14 } & \text { LF15 } & \text { LF16 } & \\ \text { LF17 } & \text { LF18 } & \text { LF19 } & \text { LF20 } & \text { LF21 } & \text { LF22 } & \text { LF23 } & \text { LF24 } & \text { low FFT 2 } \\ \text { LF25 } & \text { LF26 } & \text { FL27 } & \text { LF28 } & \text { LF29 } & \text { LF30 } & \text { LF31 } & \text { LF32 } & \text { U pod 3 / W pod 2 } \\ \text { LF33 } & \text { LF34 } & \text { LF35 } & \text { LF36 } & \text { LF37 } & \text { LF38 } & \text { LF39 } & \text { LF40 } & \\ \text { LF41 } & \text { LF42 } & \text { LF43 } & \text { LF44 } & \text { LF45 } & \text { LF46 } & & & \\ & & & & & & & & \\ \text { HF01 } & \text { HF02 } & \text { HF03 } & \text { HF04 } & \text { HF05 } & \text { HF06 } & \text { HF07 } & \text { HF08 } & \text { high FFT 1 } \\ \text { HF09 } & \text { HF10 } & & & & & & & \text { W pod 1 / W pod 3 } \\ \text { HF01 } & \text { HF02 } & \text { HF03 } & \text { HF04 } & \text { HF05 } & \text { HF06 } & \text { HF07 } & \text { HF08 } & \text { high FFT 2 } \\ \text { HF09 } & \text { HF10 } & & & & & & & \text { W pod 2 / W pod 4 } \\ & & & & & & & & \text { garbage filler to get } \\ \text { GB01 } & \text { GB02 } & \text { GB03 } & \text { GB04 } & \text { GB05 } & \text { GB06 } & & & \text { 240 byte records. }\end{array}$

Table 5: BASS Event Record Data Format

EE 38

DA HR MN SC

V11- V12- V13- V14-

V21- V22- V23- V24-

V-1- V32- V33- V34-

V41- V42- V43- V44-

V51- V52- V53- V54-

V61- V62- V63- V64-

PRESS-

$\mathrm{Zn}$
Header, keyword and length, 58 bytes ASCII time

Velocity components

Pressure, 3 bytes

Compass, 1 byte ( 7 bit inverted Grey code) 
right, and truncated to a single byte so the top bits are lost. There is no scaling used in this treatment, its purpose being to track energy at time scales shorter than 30 minutes. Actual velocities can be reconstructed from the means.

Temperatures are approximately the integer values times 8 millidegrees per bit. They are zero at $6^{\circ} \mathrm{C}$ and full scale $(\mathrm{FFFF})$ at $14^{\circ} \mathrm{C}$. Offsets between thermistors can be determined from the Sausalito dock test when the velocity sensors were bagged as the thermistors were bundled together. The thermistors were also calibrated in a controlled temperature bath after the cruise. This calibration provides the corrections needed to obtain absolute temperature measurements.

Sea Tech $25 \mathrm{~cm}$ transmissometers were modified by adding $20 \mathrm{~cm}$ of clear Plexiglas to the path to shorten them to $5 \mathrm{~cm}$ instruments to accommodate the high turbidities (150 milligrams/liter) expected during sediment transporting events. The scaling of the voltage output of the transmissometers is 0000 for 0 volts to FFFF for 5 volts. Due to the optical crudity of the pathlength shorteners, no absolute calibration is reasonable but a dollop of coffee cream in a bathtub full of tap water halves the transmission with the plastic shorteners and reduces the transmission without the shorteners by a factor of fifty. A second dollop reduces the transmission with the shorteners by another factor of two. Clean tapwater gives the same output with or without the shorteners.

The pitch and roll sensors are Humphrey pendulum angle transducers with a range of plus and minus $45^{\circ}$. They are driven with a precise 2 volt reference but scaled with the transmissometers, thus a reading of 0000 corresponds to $-45^{\circ}$ and 6666 hex to $+45^{\circ}$. Pitch is defined as positive if the BASS connector endcap is down. This would mean the upper A transducer would be moving down. Roll, measured about the long axis of the BASS electronics case, is positive for rotation clockwise looking at the connector endcap from inside the case. This corresponds to the upper B transducer moving down. Level is determined by the records from the dock test before the tripod was placed in the water in Sausalito.

The BASS electronics case with the inverted grey code compass reads zero degrees when the $\mathrm{AC}$ axis is aligned to magnetic north with the A transducer on the upper sensor ring north. The acoustic modem points $30^{\circ}$ left $\left(-30^{\circ}\right)$ of the BASS case. Thus the modem beam is in the direction indicated by the compass less $30^{\circ}$.

\subsection{Telemetry}

The telemetry planned for STRESS combined automatic transmission of the half hourly averages described in section 2.1, and operator commanded 25.6 minute transmission of "events". An acoustic modem developed by Dr. Rodney Coates (University of East Anglia) for this experiment was used to send data at 1200 baud as a FSK signal with $27 \mathrm{kHz}$ for the spaces and $33 \mathrm{kHz}$ for the marks. The transducer had a $25^{\circ}$ beam width to the 3 $\mathrm{db}$ points and was tilted upward $25^{\circ}$ from the horizontal on the tripod. The center of this beam intersected the surface at approximately 200 meters or 0.10 nautical miles (nm) from the tripod coordinates. A radio buoy to receive the acoustic signal and re-transmit it by VHF 
FM radio to shore was to have been moored in the center of this ensonified area. The transmitter would key upon detection of the acoustic signal, relay the averages and FFTs and also the last and next to last averages and FFTs to shore where they would be stored on computer disk. Figure 5 shows the command and data transmission paths used in this telemetry system. Figure 6 shows the radio buoy in the configuration used in STRESS. The extension to the bottom was added to accommodate more batteries for longer data transmission time. Figure 7 shows the desired deployment configuration for the buoy and tripod.

The radio buoy received radio signals as well as transmitted them and could be commanded to send an acoustic code to the BASS tripod. This command was transmitted by a $12 \mathrm{kHz}$ transceiver mounted on the side of the buoy hull. The acoustic command receiver on the tripod decoded these commands and triggered event data transmission for 25.6 minutes or for eight 25.6 minute cycles one hour apart, depending on whether a command 1 or a command 2 was sent. The event transmission started on the first half hour after the command was sent. An event transmission consisted of a record every $600 \mathrm{~ms}$ containing time, velocity, pressure, and compass. It is the same record from which the Tattletale computed FFTs.

Since the acoustic transmitter's orientation is not known once the tripod is deployed, an acoustic survey was used to find the ensonified area. The radio buoy was put in the water and towed through a number of positions at a range of $0.4 \mathrm{~nm}$ from the tripod's position with the signal from BASS being picked up only from the south and west. A second set of measurements was made at a range of $0.14 \mathrm{~nm}$ and only southerly and westerly positions relayed data. A weak transmission was monitored directly above the tripod as well. The data received were not decodable since we were never directly in the acoustic beam of the modem, and the correct launch site could not be determined. However, because of the direction of the acoustic signal, a reasonable estimate of the actual compass reading was possible.

During the acoustic survey, work on the deployment leg, the buoy was damaged beyond repair and could not be used for the first half of the STRESS experiment. Before the buoy was lost, the command procedure was shown to work, and the general direction of the acoustic beam (southwest) was established. A second Radio Buoy was completed in time to be deployed in March long enough to acquire event data records, and prove that the acoustic telemetry system worked in a coastal application. 


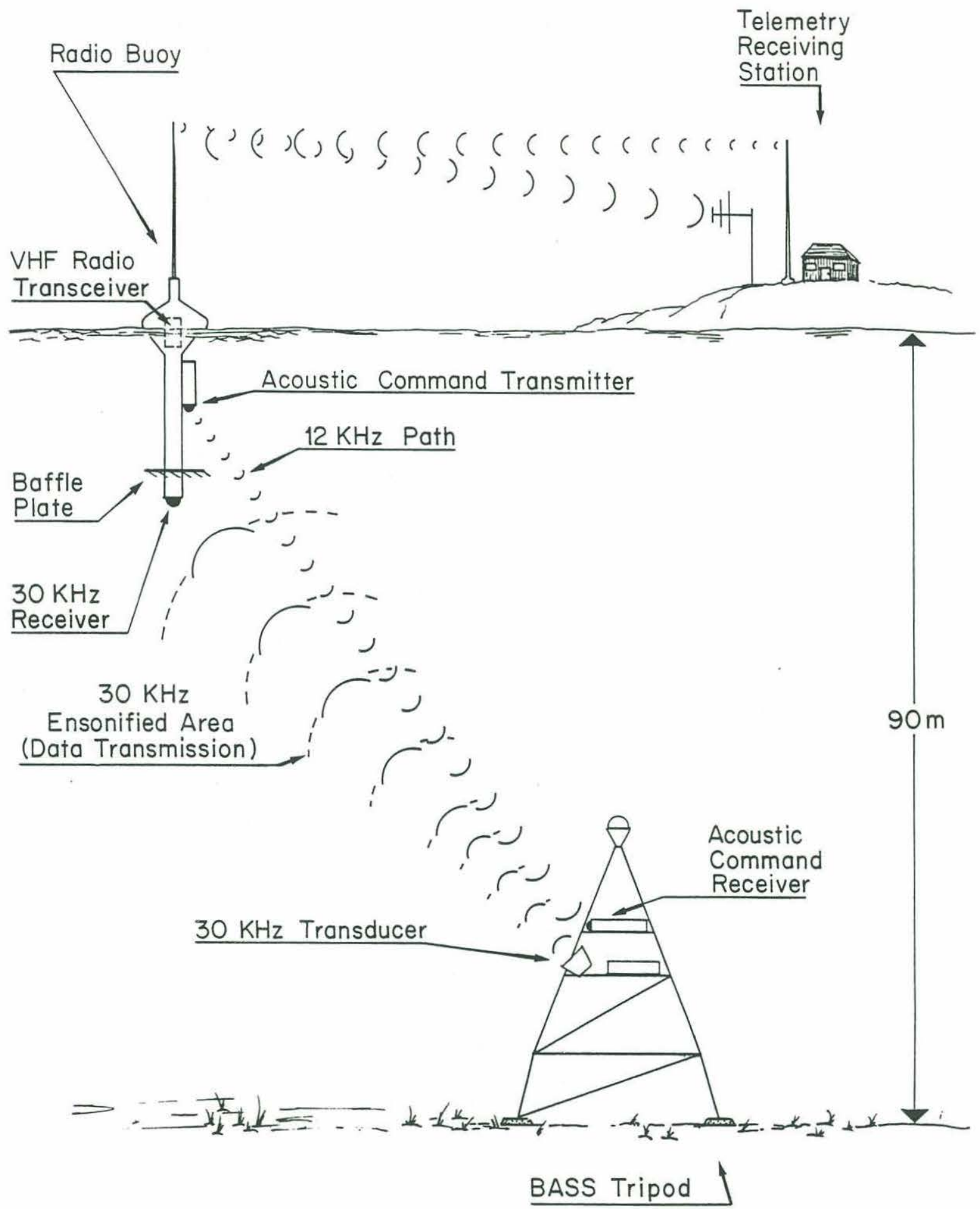

Figure 5: Schematic of Command and Data Transmission Paths 


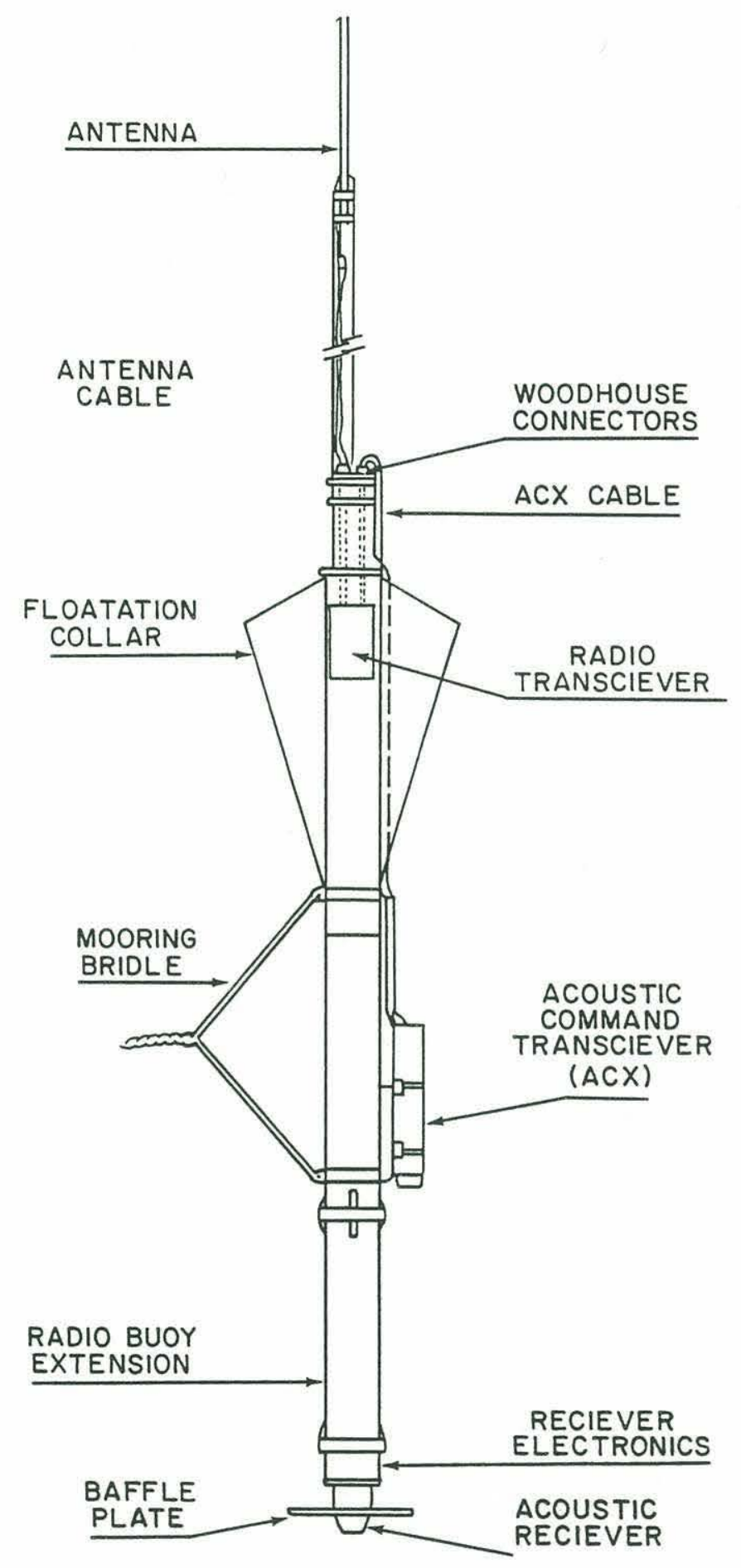

Figure 6: Telemetry Buoy Configuration 


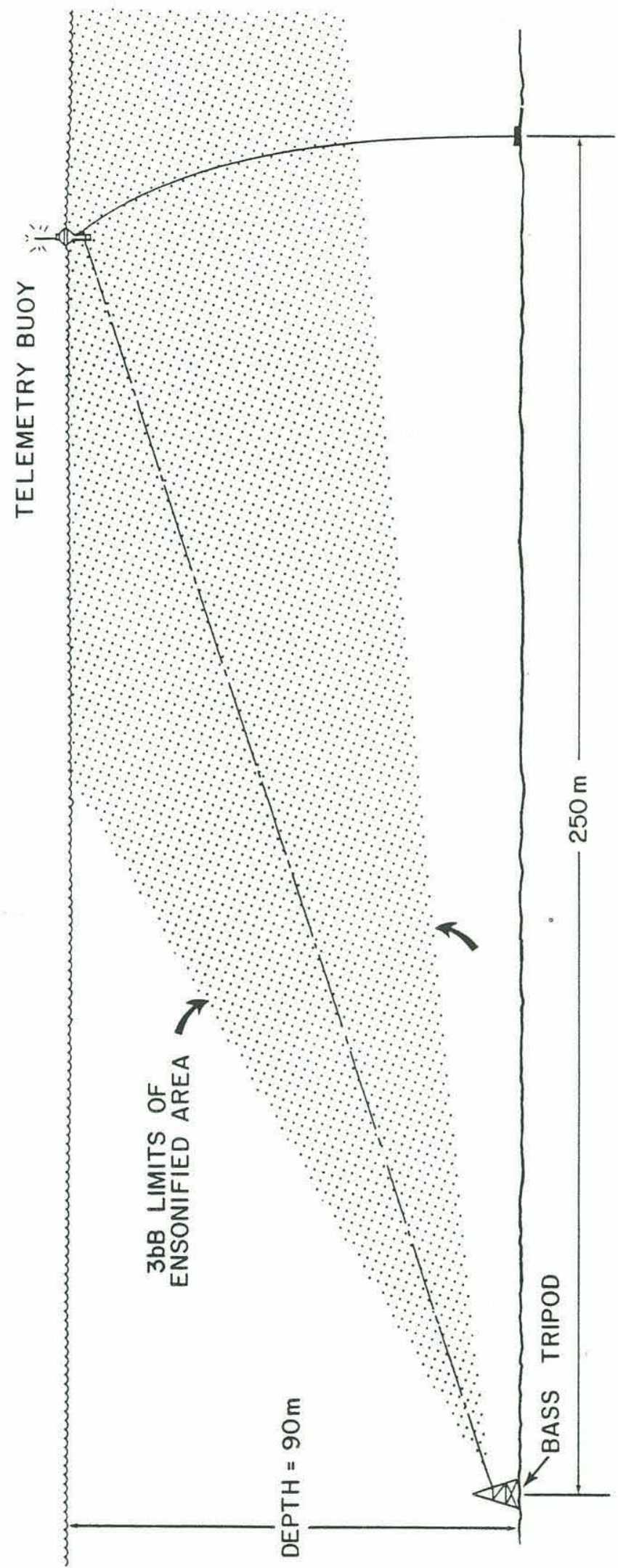

Figure 7: Telemetry Buoy and Tripod Deployment Configuration 


\section{Preliminary Results}

Averaged and FFT data were logged internally by the BASS on the C3 tripod between 1930 November 28, 1988, and 1000 March 18, 1989, with about 30 hours of data missing when the tripod was serviced on January 25. There were two event records, containing unaveraged BASS data, telemetered by the original radio buoy on November 28 at 1530 and 1730. The data in these records was so badly corrupted that no specific records were recognizable. Therefore, compass had to be derived from the positions where the radio buoy reception was the best. A value of $270^{\circ}$ was used to convert the velocities to true compass coordinates, although this estimate could be off by as much as $30^{\circ}$.

During the second half of the deployment, a new Tattletale program was used that controlled the acquisition of three events, stored in RAM, along with the logging of average data to cassette. These events were taken February 1, 3, and 5 at 1000 GMT. The compass heading was obtained from the event records $(0 \mathrm{E}=264)$. The telemetered data from March 13 were much better than the first deployment. We were able to confirm the compass heading from this data.

The auxiliary sensors on the BASS tripod worked with a few exceptions. Excellent temperature records were obtained from six of the eight thermistors. Only the lowest two thermistors appeared to have failed. The pressure and attitude sensors performed flawlessly during the experiment. The tripod mounted camera did not function so no bottom photographs were obtained at the C3 location.

Zeros completed at the dock in November were used to calibrate the C3 BASS for the first deployment. Another set of dock zeros completed after recovery were used to calibrate the data from the second deployment. The zero data were similar, so the C3 BASS did not drift significantly during the time it was deployed. The thermistors were calibrated pre-cruise, but the circuitry had to be changed subsequently, so the calibrations were no longer applicable. A post-cruise zero was done in Woods Hole to apply to the entire set of thermistor data.

The LDV tripod, in shallower water did not have a BASS on it during the first deployment. When the tripod was on deck during the turn-around, a four sensor BASS was attached to the tripod. This BASS only had three thermistors, but was otherwise instrumented as the C3 BASS was. Average data was logged to Sea Data cassette between January 25, and March 17. The C3 BASS Tattletale program was also used on this BASS, so event data from 1000 GMT on February 1, 3, and 5 was stored in RAM. There was no acoustic or radio telemetry equipment associated with this tripod. The compass value was obtained from the event records. The BASS on the LDV tripod was also zeroed post-cruise at the dock in Sausalito, and the thermistors were calibrated in Woods Hole.

The time series of uncorrected temperatures is shown in Figure 8. The transmission data shown in Figure 8 shows that large temperature variance is correlated with changes in transmission characteristics. This figure will be used to target areas of greater interest for more indepth analysis. 


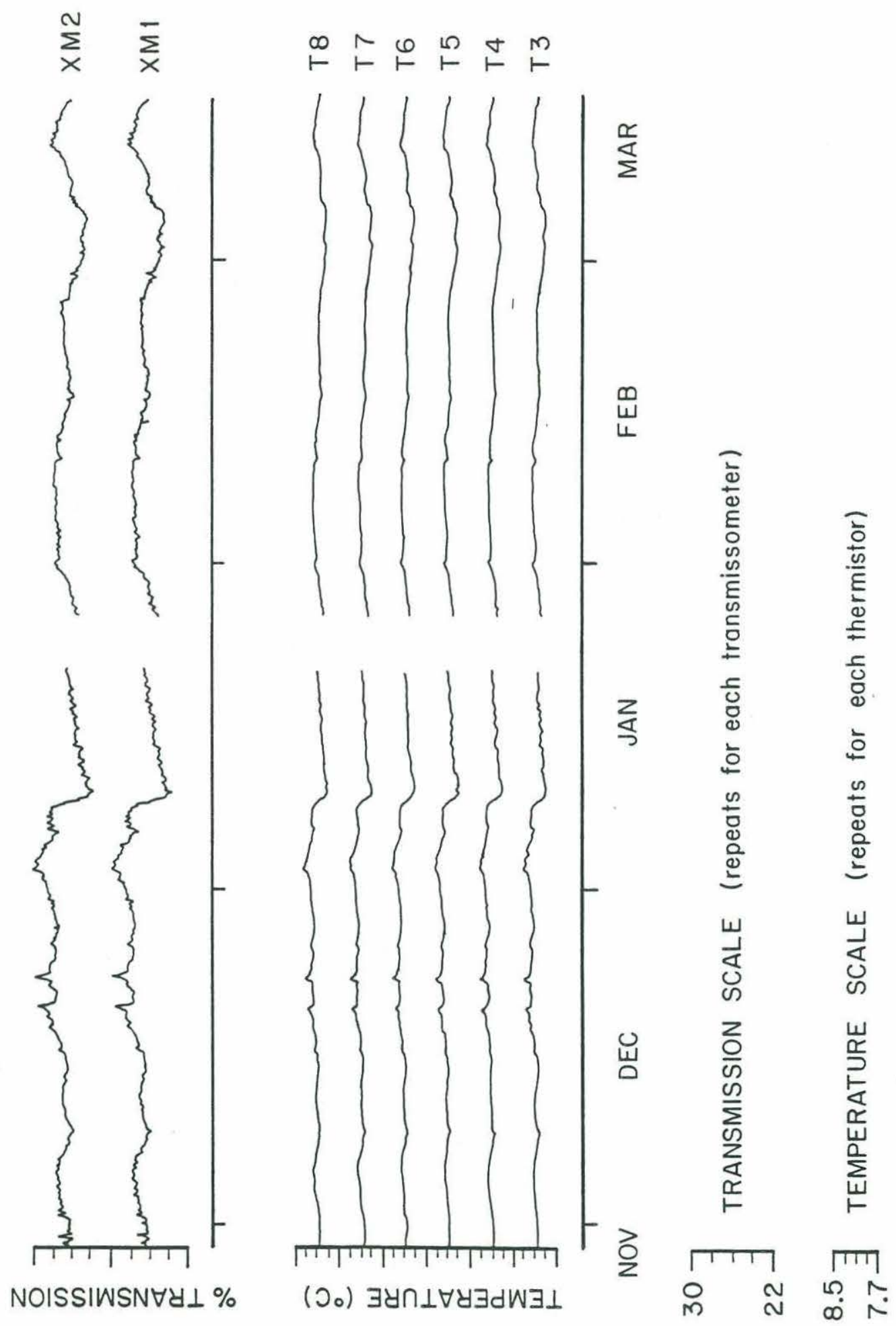

Figure 8: Time Series of Uncorrected Temperature and Transmision Data from the C3 BASS Tripod. 


\section{Cruise Reports}

The following sections document the work performed during the three cruises of the STRESS field program. The original documents were cruise reports filed immediately following each leg of the cruise. They are presented here in an edited form, preserving the maximum information to detail the actual field experience.

\subsection{Deployment Cruise Report For R/V WECOMA - Nov. 27-30, 1988}

\subsubsection{SMILE Leg 3/STRESS Leg 1}

The first priority of the cruise was to get SASS deployed. A more complete description of SASS related work is in the WHOI Technical Report, WHOI-89-34 by Montgomery and Santala, 1989. The SASS was deployed November 27 in the evening at $38^{\circ} 38.88 \mathrm{~N}, 123^{\circ}$ $29.32 \mathrm{~W}$ and the marker buoy was set at $38^{\circ} 38.98 \mathrm{~N}, 123^{\circ} 29.40 \mathrm{~W}$. Radio transmission of data from SASS was commanded on the ship and verified to be correct.

Requirements for the first leg of the STRESS cruise were to set the BASS tripod and Radio buoy and to obtain CTD sections for cross shelf and near bottom mixing studies. The BASS tripod is a structure $21 \mathrm{ft}$ tall, $15 \mathrm{ft}$ on a side, that sits on the bottom measuring fluid velocities in the bottom 5 meters of the water column to determine stress responsible for sediment transport.

The BASS tripod was free dropped November 28 at 1230 in 91 meters of water at $38^{\circ}$ $38.51 \mathrm{~N}, 123^{\circ} 29.47 \mathrm{~W}$. Its acoustic transducer for the modem that relays data to the radio buoy was pointed south. The tripod contained an Oceanographic Instruments Systems (OIS) Acoustic Command Release (ACR) \#2165 listening at $12 \mathrm{kHz}$ for address 0101. Its backup timer was set for March 20, 1989 at 1200 PST. An OIS Timer Pinger (T/P) \#126 was set to start pinging March 19, 1989 at 1200 PST and release 24 hours later. The release was a float carrying a $\frac{1}{2}$ inch Dacron line to the surface with which the tripod can be raised.

The radio buoy was deployed and towed to receive signals from the BASS tripod beginning November 28 about 1330. A series of locations at which signals were received and another series at which they were not indicated that the acoustic beam from BASS was directed between south and west. The radio buoy was recovered for the night (approx. $2000 \mathrm{~h}$ ) without receiving a clear enough signal to decode the BASS compass.

CTD profiles with a new EG\&G Smart CTD were started at 2200. A section was run just north of the $\mathrm{C}$ line from 50 meters depth to $10 \mathrm{~km}$ offshore with 6 stations separated by $2 \mathrm{~km}$. The ship hove to on November 29 from 0100 until 0800 when radio buoy operations resumed.

The radio buoy was put over the side at 0830 on November 29 at $38^{\circ} 38.18 \mathrm{~N}, 123^{\circ} 29.50$ $\mathrm{W}$ to start an arc of positions at a range of $0.25 \mathrm{~nm}$ from the BASS tripod on 20 degree intervals from south to west. The acoustic transmission at 0830 was just missed and we held station for the 0900 transmission. At 0850 , the radio buoy was dragged under the ship by a bight of line that fouled the propeller. When it resurfaced a minute later, it had lost the 
acoustic modem receiver attached to its lower end and was broken and flooded. The acoustic command transmitter to control event record transmission on BASS had been torn off the buoy hull. Only the radio antenna was undamaged. The buoy was recovered and the BASS operations terminated.

The propeller and shaft seals were checked by a speed run offshore. Then a survey of buoy positions in the $\mathrm{C} 3$ area was made by a tour through the array. Time differences from Loran $\mathrm{C}$ were obtained with each buoy about $20 \mathrm{ft}$ abeam. The positions follow:

\begin{tabular}{lrrr}
\multicolumn{1}{c}{ Buoy } & W TD & X TD & Y TD \\
C3 Met Buoy & 15695.13 & 26999.94 & 43440.06 \\
C3 Backup & 15695.34 & 26999.97 & 43440.07 \\
SASS & 15695.30 & 27000.00 & 43440.62 \\
SASS Backup & 15694.56 & 27000.05 & 43440.96 \\
BASS Crab Buoy & 15696.25 & 26999.88 & 43439.17 \\
Waverider & 15697.99 & 26999.87 & 43438.83
\end{tabular}

At 1100 , CTD sections were started just north of the $\mathrm{C}$ line starting at 50 meters depth, every $2 \mathrm{~km}$, for $10 \mathrm{~km}$. The stations were occupied continuously for 12 hours. They were all done from shallow to deep. At 2300 we proceeded to the start of a second section $10 \mathrm{~km} \mathrm{SE}$ along the coast starting at 50 meters depth. A single section was run with spacing of $2 \mathrm{~km}$ out to $10 \mathrm{~km}$. This section was finished at 0300 November 30 . We then departed for Bodega Bay to be inspected by divers for propeller damage. We were at the dock in Sausalito at 1630 .

\subsubsection{STRESS - Leg 2: December 1-6, 1988}

WECOMA left Sausalito for the STRESS site off Sea Ranch, CA at 0730 December 2, 1988. The purpose of this leg was to deploy two tripods and continue CTD surveys connected with the STRESS program. The first tripod was to use sonar to measure the effect of sediment transport on bottom acoustic scattering. This tripod was under the direction of Darrell Jackson of APL-U Wash. The second tripod was to measure the suspended sediment itself, its particle size, settling velocity, vertical distribution, and to obtain physical samples of the sediment laden water. The CTD profiles were to study internal wave activity on the shelf and the structure of the stratification across the shelf.

On December 2, two attempts were made to launch the Sonar tripod without success. On the first attempt, the recovery release parted and the tripod was placed back on the deck for repair, on the second attempt, it was lowered to the bottom on a line with an electrically operated release for the lowering line but the line became open at pressure. The operation was stopped because of darkness. It was resumed the morning of the $3 \mathrm{rd}$ with a slipline in place of the electrical release and this launch was successful. The tripod was aligned with its forward direction facing south. A line to a weighted target attached to the backside leg was tended by the inflatable boat and pulled north during the lowering. Subsequent acoustic tests verified the tripod was working and pointing south. 
A 12 hour CTD yo-yo station was run during the night of December 2-3 at 90 meters near C3. While on station, several attempts were made to hear BASS, launched on the previous leg, by lowering a hydrophone over the side at the half hour modem transmission time. The CTD profiles showed a bottom boundary layer in which there was higher turbidity. A CTD section from 50 meters depth out $20 \mathrm{~km}$ depth was run for 12 hours the night of December 3-4. A 12 hour CTD yo-yo station was run at 50 meters depth the night of December 4-5. These stations were taken by Jim Lynch with an EG\&G Smart CTD with Sea Tech transmissometer.

During the day after the Sonar tripod was deployed, acoustic checks were made on BASS and the Sonar tripod. BASS was determined to be transmitting with its acoustic modem at a bearing of about 280 degrees. The Sonar tripod was determined to be pointing south.

SASS, which was deployed on the previous leg, had stopped sending data although it could be commanded and keyed its radio transmitter. SASS was recovered the afternoon of December 3 and repaired that night. It was redeployed the afternoon of December 4 with its batteries recharged and appeared to be working well.

The Sediment tripod, with four PIs involved, was held to the last possible launch time to permit the ABSS systems to be debugged. The final corrections were made during the night of December 5-6 and it was launched the afternoon of December 6. Also mounted on the tripod were Sternberg's OBS managed by Chris Sherwood, Sea Tech's ROST managed by Mark Borgerson, and Agrawal's LISST mounted in Sausalito and launched in absentia.

A final inspection of the buoys along the $\mathrm{C}$ and $\mathrm{M}$ lines was made the afternoon of December 5 and we left for Sausalito in the evening for a morning December 6 tide at the Richardson Channel.

\subsubsection{STRESS - Leg 3: December 7-9, 1988}

WECOMA left Sausalito at 0800 December 7, 1988 for the third leg of STRESS. The princial task was to set the LDV tripod and recover the SASS buoy deployed on the first leg.

The LDV measures velocity within a few centimeters of the bottom and thus observes the local boundary shear stress. Agrawal's instrument triggers on wave induced pressure fluctuations. The LDV is turned on when the variance of pressure exceeds a threshold which is raised each time it is exceeded. Thus there is a starting condition that will be exceeded in even moderate waves but the waves must be greater for a second event and 20 times as great for the eighth event. Relatively clear water is required for the LDV to obtain a signal. For this reason, it was placed in 53 meters of water on a sand patch near Dave Cacchione's Geoprobe, where the water should be less turbid then at 90 meters under storm waves.

We received word before sailing that the signal from the Waverider, which had been installed on the last SMILE leg, was not being received ashore. A new antenna was taken to Sea Ranch by Chris Sherwood to rectify the difficulty. Chris returned shortly before sailing with the receiving station and the news that the problem might very well be in the receiver. 
The Waverider became one extra task for the third leg.

Bob Beardsley requested that we calibrate the Research and Development Instruments (RDI) Acoustic Doppler Current Profiler (ADCP) used in SMILE, by making along contour and cross contour runs and their reciprocals during good GPS reception periods (3 to 7 a.m.). This became the second additional task.

As we approached the $\mathrm{C} 3$ site, we observed a recovery float on the surface. It appeared to be ABSS. This was a prerelease and the tripod had to be recovered, the problem discovered and fixed, and the tripod reset. The backup buoy on SASS was not visible although a crab buoy tethered to the main float was stuck on one of the floats. This was seen to be a complication that might require swimming, free-diving, or scuba diving to remedy.

It was blowing 20 to 30 knots on our trip to $\mathrm{C} 3$ and the sea was still too rough to do any work on the tripod or on recoveries so we did a 12 hour CTD station in 90 meters near C3 and ABSS through the night until 0500. When the CTD yo-yos were completed, GPS fixes were coming in well so we made two runs to calibrate the RDI ADCP. At 0853 we launched the LDV tripod in 53 meters of water. Coordinates of the LDV tripod are $38^{\circ} 37.34 \mathrm{~N}, 123^{\circ}$ $23.51 \mathrm{~W}$. After the launch, we picked up a cluster of buoys that Farnella had left to mark the spot.

We picked up the ABSS recovery float and had ABSS aboard at 1045. Its acoustic command release had timed out thinking it was March 20, 1989 due to being left in test mode on November 26 when it was set. Release must have occurred within 30 minutes of launch. At 1342 , it was relaunched at $38^{\circ} 38.70 \mathrm{~N}, 123^{\circ} 29.53 \mathrm{~W}: \mathrm{W}=15695.33 \mathrm{Y}=43439.88$.

Tests with the Waverider receiver and receiver calibrator failed to resolve where the problem with the Waverider signal lay. The calibrator was not working, so its failure to excite the receiver could not be attributed to receiver failure. The receiver's failure to receive the Waverider signal could not necessarily be attributed to the Waverider either. Since there would be no one at Sea Ranch until the turnaround cruise in late January, the Waverider was recovered. This was done by hooking the buoy, lifting it aboard with the crane, taking in on the rubber section of the mooring line with the capstan until the rope section was encountered, and then taking the rope in by winch through the $\mathrm{A}$ frame. The Waverider was aboard at 1445 and recovered at $38^{\circ} 38.40 \mathrm{~N}, 123^{\circ} 29.23 \mathrm{~W}: \mathrm{W}=15697.59, \mathrm{Y}=43433.73$.

A run to the LDV tripod launch site was made while the deck was cleared for SASS recovery. No surface float was seen at the LDV site, ensuring that the tripod had not suffered from a premature release.

By the time we returned to the SASS site, the backup buoy had surfaced, although it was towing under frequently. We hooked the line beneath the float, pulled with the capstan, tied off on a cleat, transferred to the winch and pulled through the A frame. About 100 feet down, we encountered the SASS mooring line, wrapped several turns around the backup buoy polypro line. The SASS line was cut, setting SASS adrift. The backup anchor was 
recovered, removed from the line, and the chain connecting the backup anchor to the main anchor was hauled on the winch. Finally the main anchor was recovered. Using the crane, SASS was recovered and secured. Recovery was at 1559 and location $38^{\circ} 38.88 \mathrm{~N}, 123^{\circ} 29.44$ $\mathrm{W}: \mathrm{W}=15694.85, \mathrm{Y}=43440.63$. With everything aboard, we left for Sausalito at 1730 . 


\subsection{Turn-Around Cruise Report R/V PT. SUR January 23-28, 1989}

Due to a schedule conflict, this cruise had to be accomplished using the PT. SUR, a somewhat smaller vessel than optimal for tripod work. The weather was favorable, and no work was missed because of the ship's size or capabilities. In fact, the crew's willingness to help out more than made up for any shortcomings of the ship. The PT. SUR proved to be an excellent ship to work from.

\subsubsection{Scientific Objective}

The objective of this cruise was to service the tripods of the STRESS experiment halfway through the deployment period. Batteries were replaced or charged and data dumped or tapes replaced. In addition, the FVSK tripod was deployed, CTD and ADCP sections were run, and box cores and camera stations were taken. A new radio buoy was to have been deployed, but problems with the modem-to-radio interface were discovered at dockside, requiring repairs beyond our ability in the field. The acoustic systems alone were fully tested from the ship, however, and found to perform adequately.

\subsubsection{Work Performed}

The FVSK or Stereo Camera, prepared by Rob Wheatcroft of U.W. in Moss Landing, was deployed at 10:28 PST January 24, 1989. The OIS acoustic command release with address 0110 was set for a backup timed release at 1500 PST March 19, 1989. The deployment location is TDX 26999.24 , TDY $43439.92,38^{\circ} 38.703 \mathrm{~N}, 123^{\circ} 29.44 \mathrm{~W}$.

Next an attempt was made to release the ABSS tripod. Each release, address 0001 and address 1010 replied and accepted a release command. At 1346 January 24, 1989 the 0001 release stopped transponding at the exact moment that voltage would have been applied to the release link implying the link was shorted to ground causing the voltage to disappear when the release relay was closed. Release 1010 behaved normally, continuing to transpond after receiving the release command and confirming it. The float failed to appear although the location of ABSS tripod was not in doubt. Presumably the release was gone or the line was fouled. The work of the cruise went on as described below, with periodic attempts to command the ABSS tripod release. A final set of release commands was sent to ABSS from 1120 PST January 27 until 1132; the commands were confirmed on address 1010 . Unfortunately, the tripod seemed very determined to stay where it was. It does seem that the ACR 0001 had shorted the burnwire to something large because the transponding stopped when the release command was received.

At 1523 January 24, 1989, the LDV tripod recovery line was released and the tripod was recovered at 1700 . The LDV tape had been written upon and the instrument looked good except for accelerated corrosion on hose clamps and v-band clamps. The LDV battery was replaced and a new tape inserted. A BASS with four velocity sensors, two transmissometers, three thermistors, and a pressure sensor was added to the LDV tripod and it was redeployed 
at $38^{\circ} 37.35 \mathrm{~N}, 123^{\circ} 23.48 \mathrm{~W}$ in 29 fathoms (52 meters) at $1330 \mathrm{PST}$, January 25,1989 . The acoustic command release, address 0111, was set for backup timed release 1200 PST March 20, 1989. A timer/pinger was set to start pinging 1010 PST March 20, 1989 and to release 1010 March 21.

While the batteries were being charged on the LDV tripod, a cable lowered hydrophone and the radio buoy discriminator was used to listen to the acoustic transmissions from the BASS tripod. Inversion of the marks and spaces on the discriminator were required to match the transmitted signal and at 0530 on January 25, an event record from BASS was recorded on the NEC IV as file STRES125.DAT and the average record following it as STRES126.DAT. This was our first successful use of acoustic telemetry in an ongoing field experiment.

A boxcore was taken the evening of January 24 for acoustic property determinations of the near surface mud. The boxcore was heavy and went too deep. After the first attempt, the core was modified with wooden stops, and samples were obtained.

After the LDV was redeployed, the BASS tripod recovery was commenced. Its float was released at 1415 and the float was on the surface at 1440. The tripod was on deck an hour later. The tripod showed corrosion in several places. Two v-band clamps had failed and at least 5 hose clamps were broken. Fortunately, cases were tied on with twine as a backup to the hose clamps. The BASS logger had a full data tape, STRESS 03, and the tape was found to be readable although we didn't have the facilities to read it to computer on the ship. No film had advanced in the camera although the trigger circuit was working. The batteries in the strobe unit were low and these were replaced. The lithium battery was still healthy but it was replaced with a new one and the alkaline pack to run the tape transport was healthy but replaced. The program in the Tattletale computer was replaced by a modified program written by Tom Gross called STRESSWK.TTB that would captured several half hours of the raw data used for the FFTs. It logs these events on Feb 1, 3, and 5 at 1000 GMT. These data can be dumped after recovery by connecting the computer to the Tattletale by the phone plug and at 1200 baud, typing W. When it answers Huh? typing AKEUP terminates program execution, so that dumping the buffers is possible.

BASS was turned on at 0830 and launched at 1230 PST January 26,1989 at $38^{\circ} 38.48 \mathrm{~N}$, $123^{\circ} 29.67 \mathrm{~W}$. Its acoustic command release, address 0101 , was set to a backup release time of 1200 PST March 20, 1989 and a timer/pinger was set to start pinging 1200 March 20 and to release 1200 March 21.

While the BASS was being turned around, another box core was taken and a 12 hour CTD station was made near the C3 Met Buoy. At 0600 January 26, we steamed to Bodega Bay to drop off Rex Johnson (University of Washington, supporting Sternberg's OBS) since he had no critical tasks to perform with the ABSS tripod unrecoverable.

We were back on station at C3 by noon and released the Scanning Sonar float at 1206 . It was up at 1225 and after deploying the BASS tripod, we picked up the sonar tripod at 1330 . The data dump from the Sonar tripod took almost 36 hours due to some difficulties with the 
D: hard disk on the tripod but all data was eventually dumped. While the Sonar tripod was being serviced, an $\mathrm{ADCP}$ run was made on the $\mathrm{C}$ line, starting at $\mathrm{C} 3$, going in to the Alpha buoy, on to the Delta buoy in a straight line, and back to C3. The ADCP calibration run started at 1340 PST January 26, turned at Alpha at 1400, detoured around fishing boats at 1450, was abeam of the Delta buoy at 1523, and was back at C3 at 1630 .

In the evening, a pattern of positions about $0.1 \mathrm{mi}$ from the BASS tripod were occupied to determine where the acoustic modem was pointing. The strongest signal was at $38^{\circ} 38.489$ $\mathrm{N}, 123^{\circ} 29.814 \mathrm{~W}$. This is almost due west of the tripod location. Following the successful determination of the acoustic transmitter's orientation, no other work was done except completing the Sonar tripod data dump.

The batteries were charged and the data was dumped by 0130 PST January 28, when the Scanning Sonar was redeployed at $38^{\circ} 38.58$ N, $123^{\circ} 29.51$ W. A slip line was used for deployment of the tripod and no target was attached as in the WECOMA deployment. The acoustic command release, address 0111, was set for backup timed release on March 19, 1989. A burst measurement was monitored at a position $0.5 \mathrm{mi}$ south of the deployed position to determine the orientation of the tripod and at 0305, we started for Moss Landing.

The following is a summary of the CTD work completed during the STRESS turn-around cruise by Jim Lynch, with the Smart CTD.

Three sets of CTD data were taken during the PT. SUR turnaround cruise: (1) three casts over two hours at the site of the LDV tripod just before it was relaunched, (2) a 12 hour yo-yo in the vicinity of the C3 met buoy, and (3) a set of six 10-Km transects over 13 hours at six stations spaced $2 \mathrm{~km}$ apart along a line perpendicular to the coast passing near the C3 met buoy. Winds were light and seas were calm during most casts.

The LDV-site casts were taken from 11:09 to 12:57 PST 1-25-89 at roughly 50-minute intervals at location $38^{\circ} 37.4^{\prime} \mathrm{N}, 123^{\circ} 23.5^{\prime} \mathrm{W}$ in $51 \mathrm{~m}$ of water.

The yo-yo set was taken from 15:52 PST 1-25-89 to 03:52 PST 1-26-89. The location was nominally at $38^{\circ} 38.7^{\prime} \mathrm{N}, 123^{\circ} 30.0^{\prime} \mathrm{W}$, but varied over a mile or so due to the necessity for the ship to maintain headway and at times for the ship to do box cores at certain locations. The water depth varied from 92 to 96 meters, and the casts reached within 5 to $10 \mathrm{~m}$ of the bottom. The interval between casts varied from 10 minutes (15:52 to $16: 52)$ to 70 minutes (18:34 to $19: 45$ during a box core) but was nominally 30 minutes (19:45 to 03:45).

Kevin Briggs (NORDA) has requested bottom temperature and salinity data from casts 12 and 13 (the second and third casts of file CTD1003.DAT) taken just after box cores 10 and 11 , respectively. Other nearby casts will do if there is a problem with these.

The six transect stations, in the order in which they were visited, had approximate locations and water depths as follows: 


$\begin{array}{cllr}\text { Station } & \text { Latitude } & \text { Longitude } & \text { Depth } \\ & & & \\ 1 & 38^{\circ} 40.19^{\prime} \mathrm{N} & 123^{\circ} 27.67^{\prime} \mathrm{W} & 74 \mathrm{~m} \\ 2 & 38^{\circ} 39.57 & 123^{\circ} 28.80 & 83 \\ 3 & 38^{\circ} 38.93 & 123^{\circ} 29.91 & 91 \\ 4 & 38^{\circ} 38.02 & 123^{\circ} 31.13 & 102 \\ 5 & 38^{\circ} 37.25 & 123^{\circ} 32.27 & 13 \\ 6 & 38^{\circ} 36.49 & 123^{\circ} 33.59 & 28\end{array}$

Each station was sampled six times between 21:42 PST 1-26-89 and 10:46 PST 1-27-89, The interval between stations was approximately 20 minutes, and the interval between resamplings of the same station was approximately 2 hours and 20 minutes.

The three or four files with filenames ending in ' $B$ ' are repeated memory dumps of the corresponding files without the 'B's. The CTD software said there was an error the first time, although most of the time the files seem to be identical. The ' $\mathrm{B}$ ' files are preferred if they are different.

The Neil Brown Smart CTD with Sea Tech transmissometer was found to have leaked through one of the lower connectors during preparation for this cruise. It was repaired by Neil Brown Instruments in time for the cruise, but there was not enough time to calibrate the CTD, so a post-calibration must be done in Woods Hole. During the cruise, the transmissometer readings seemed suspect ( $2.054 \mathrm{~V}$ dark, $3.964 \mathrm{~V}$ air), so the transmissometer was disconnected from the CTD and connected to a separate $12 \mathrm{~V}$ power supply. The signal readings taken with a digital multimeter ( $0.006 \mathrm{~V}$ dark, $4.730 \mathrm{~V}$ air) are within the acceptable range, suggesting that the A/D converter in the CTD is either severely miscalibrated or not working at all. 


\subsection{Recovery Cruise Report}

\section{R/V WECOMA March 12-23, 1989}

The recovery work for STRESS and SMILE was performed from the R/V WECOMA working out of Sausalito, CA. A total of three legs were required to retrieve all of the bottom tripods and surface buoys which we had deployed. The following is a description of the work performed, not an actual log with accurate dates and times. No recovery log was maintained during the field work.

\subsubsection{Leg 1: March 12-14, 1989}

The purpose of Leg 1 was to begin recovery operations of the STRESS tripods and the Surface Acoustic Shear Sensor (SASS) mooring. The WECOMA left Sausalito late on March 12th and arrived at the STRESS site early on the 13th. Our first task was to deploy the new radio telemetry buoy for sea trials. We steamed to the desired location and verified that the BASS instrument on the bottom was sending data through its acoustic modem. Once this was accomplished, the buoy was launched. The buoy was used to activate the BASS instrument throughout the day and event data records were recorded on the personal computer onboard the ship.

Once the radio buoy was in the water, we turned our attention to tripod recoveries. We brought two aboard: Arthur Nowell's Free Vehicle Stereo Camera (FVSK), which had been launched from the PT. SUR in January, and the Scanning Sonar (SS) tripod which had been deployed by Darrell Jackson's group. Both recoveries were normal and the instruments were transferred to the 01 deck level for storage.

The final recovery of the trip was the SASS mooring and buoy. The ship's crew was enlisted for additional manpower and the fantail cleared to make room for the buoy. The recovery effort went very smoothly, with the entire mooring coming aboard without damage. The buoy was brought aboard and secured for the return trip to Sausalito. Once the buoy was lashed to the deck, we did notice that one waist element was missing, that some of the bolts fastening the nodes attaching these elements had loosened, and that stress cracking had occurred where the float support struts connected to the main risers. Cracking had occurred previously in the same areas and been repaired by rewelding. It is now apparent that the structure will require additional strengthening in the area where these struts attach.

Once the equipment was secured, the WECOMA began a slow transit to Sausalito, arriving in time for the morning tide.

\subsubsection{Leg 2: March 17-19, 1989}

The purpose of the second recovery leg was to retrieve all of the tripods that could be recovered normally. This was done to identify any other candidates for ROV recovery operations. The BASS tripod at the C3 site, and Agrawal's LDV tripod at the shallow station were both recovered normally during this cruise. One interesting note is that the recovery 
lines for both tripods had thrown a loop under the strobe attachment bracket of the lifting bail. The Samson line had chafed through its outer jacket where it was pinched, and would have failed if the recovery had not proceeded as quickly as it did once the tripods were on the surface. Kudos to all involved in the recovery effort for their quick actions on the ship which prevented the loss of equipment.

The BASS tripod was observed to be covered with a fine layer of bottom mud over its entire height. The stainless hose clamps securing the instruments to the tripod had failed, as had most of the Vee Band clamps securing the end caps. Alternate methods for attaching and closing instruments will be required for future deployments of more than several weeks in similar nearshore applications.

The radio buoy was also recovered on this leg. The recovery was not as smooth as the others because there were some problems with the mooring design that became apparent on retrieval. In particular, there was no method for removing the tension from the mooring line in order to unshackle the buoy. The rubber bungee cord section of the buoy mooring snapped during recovery, and could have easily injured someone on deck. A second float attached to the anchor or tension member below the bungee cord would simplify the recovery procedure, and greatly increase safety on the deck.

\subsubsection{Leg 3: March 21-23, 1989}

The final leg of the recovery cruise was reserved for ROV operations. The only tripod which had failed to surface normally was Lynch's ABSS tripod. This unit had experienced problems during the January cruise aboard the PT. SUR, and was now scheduled for pickup.

The assistance of Deep Ocean Engineering, San Leandro, CA, in supplying one of their Phantom line of ROV's and allowing Rodney Moore, who is an experienced operator, to accompany us was invaluable for this recovery. Land and Sea Survey Co., Venture, CA, supplied the navigation system that allowed us to position the ROV close enough to the tripod for its cameras to find the target and attach a lifting hook to the tripod. We very much appreciate the efforts of both these fine companies.

The WECOMA left Sauasalito late on the 21st under a nearly full moon. Arriving on station early the next morning the ship was navigated into position using an acoustic system which displayed the locations of the ship, the tripod on the bottom, and a pinger attached to the ROV down lead. Once launched, the ROV operator acquired the tripod almost immediately with a small scanning sonar unit on the vehicle and, shortly after that, with the vehicle's video camera. A recovery line was attached to the tripod's lifting bail, the ROV was recovered, and the tripod was then winched to the surface for retrieval.

The final task for the third leg was to attach safety lines to the Vector Averaging Wind Recorders (VAWR) deployed by the Scripps buoy group. A recorder had been lost, and it was felt that safety lines were required for the three remaining units. These lines were attached by a party working from a small boat. At dusk, the boat was recovered, and the WECOMA 
began a slow transit to Sausalito, arriving in port the next morning.

An interesting note is added to this record months later. The VAWR which had disappeared from one of the four Scripps surface moorings was never recovered. The other three survived their deployment. When the buoy which had the missing recorder on it was recovered, evidence of collision with a vessel was found on the support ring for the VAWR. The team recovering the buoy felt certain that the loss of the VAWR was due to this collision.

\section{Acknowledgements}

Many people contributed to the success of this project, and we appreciate their combined efforts. We wish to thank specifically the following individuals: Ms. Daphne Derven of the Bay Model Visitor Center for making that facility available to us for staging, which saved us days of ship time due to its proximity to the experimental area; Dr. Sylvia Earle and Mr. Rodney Moore of Deep Ocean Engineering for supplying and flying the R.O.V. that allowed recovery of the ABSS tripod; the crews of th R/V WECOMA and R/V PT. SUR, whose competent ship handling and willingness to assist made the cruises successful; and finally, Judith White for word processing this manuscript. This work was accomplised under ONR contract N000-14-89-J-1058.

\section{References}

Dunn, C.V.R. and A.G. Gordon, 1989. "A Pop-up Float Recovery System for Coastal Oceanographic Tripods". WHOI Tech. Rept., in prep.

Montgomery, E.T. and M.J. Santala, 1989. "The Surface Acoustic Shear Sensor (SASS) As Used During The Shelf MIxed Layer Experiment (SMILE), November 1988 - March 1989". WHOI Tech. Rept., 89- 34.

Williams, A.J. 3rd, J.S. Tochko, R.L. Koehler, W.D. Grant, T.F. Gross and C.V.R. Dunn, 1987. "Measurement of Turbulence in the Oceanic Bottom Boundary Layer with an Acoustic Current Meter Array". J. of Atmos. and Oceanic Tech., 4(2), pp. 312-327. 


\section{DOCUMENT LIBRARY}

July 5, 1989

Distribution List for Technical Report Exchange

Attn: Stella Sanchez-Wade

Documents Section

Scripps Institution of Oceanography

Library, Mail Code C-075C

La Jolla, CA 92093

Hancock Library of Biology \& Oceanography

Alan Hancock Laboratory

University of Southern California

University Park

Los Angeles, CA 90089-0371

Gifts \& Exchanges

Library

Bedford Institute of Oceanography

P.O. Box 1006

Dartmouth, NS, B2Y 4A2, CANADA

Office of the International

Ice Patrol

c/o Coast Guard R \& D Center

Avery Point

Groton, CT 06340

Library

Physical Oceanographic Laboratory

Nova University

8000 N. Ocean Drive

Dania, FL 33304

NOAA/EDIS Miami Library Center 4301 Rickenbacker Causeway

Miami, FL 33149

Library

Skidaway Institute of Oceanography

P.O. Box 13687

Savannah, GA 31416

Institute of Geophysics

University of Hawaii

Library Room 252

2525 Correa Road

Honolulu, HI 96822

Library

Chesapeake Bay Institute

4800 Atwell Road

Shady Side, MD 20876

MIT Libraries

Serial Journal Room 14E-210

Cambridge, MA 02139
Director, Ralph M. Parsons Laboratory Room 48-311

MIT

Cambridge, MA 02139

Marine Resources Information Center

Building E38-320

MIT

Cambridge, MA 02139

Library

Lamont-Doherty Geological

Observatory

Colombia University

Palisades, NY 10964

Library

Serials Department

Oregon State University

Corvallis, OR 97331

Pell Marine Science Library

University of Rhode Island

Narragansett Bay Campus

Narragansett, RI 02882

Working Collection

Texas A\&M University

Dept. of Oceanography

College Station, TX 77843

Library

Virginia Institute of Marine Science

Gloucester Point, VA 23062

Fisheries-Oceanography Library

151 Oceanography Teaching Bldg.

University of Washington

Seattle, WA 98195

Library

R.S.M.A.S.

University of Miami

4600 Rickenbacker Causeway

Miami, FL 33149

Maury Oceanographic Library

Naval Oceanographic Office

Bay St. Louis

NSTL, MS 39522-5001

Marine Sciences Collection

Mayaguez Campus Library

University of Puerto Rico

Mayagues, Puerto Rico 00708 


\begin{tabular}{|c|c|c|c|}
\hline $\begin{array}{l}\text { REPORT DOCUMENTATION } \\
\text { PAGE }\end{array}$ & $\begin{array}{l}\text { 1. REPORT NO. } \\
\text { WHOI-89-56 }\end{array}$ & 2. & 3. Recipient's Accession No. \\
\hline \multirow{2}{*}{\multicolumn{3}{|c|}{$\begin{array}{l}\text { 4. Title and Subtitle } \\
\text { Report on Sediment TRansport Events on Shelf and Slope (STRESS) } \\
\text { Field Season 1: Winter 1988-1989 - Benthic Acoustic Stress Sensor (BASS) Component }\end{array}$}} & $\begin{array}{l}\text { 5. Report Date } \\
\text { December, } 1989\end{array}$ \\
\hline & & & 6. \\
\hline \multicolumn{3}{|c|}{$\begin{array}{l}\text { 7. Author(s) } \\
\text { Ellyn T. Montgomery, C.V.R. Dunn, A.J. Williams 3rd }\end{array}$} & $\begin{array}{l}\text { 8. Performing Organization Rept. No. } \\
\text { WHOI-89-56 }\end{array}$ \\
\hline \multirow{2}{*}{\multicolumn{3}{|c|}{$\begin{array}{l}\text { 9. Performing Organization Name and Address } \\
\text { The Woods Hole Oceanographic Institution } \\
\text { Woods Hole, Massachusetts } 02543\end{array}$}} & 10. Project/TaskWWork Unit No. \\
\hline & & & $\begin{array}{l}\text { 11. Contract(C) or Grant(G) No. } \\
\text { (C) N000-14-89-J-1058 } \\
\text { (G) }\end{array}$ \\
\hline \multirow{2}{*}{\multicolumn{3}{|c|}{$\begin{array}{l}\text { 12. Sponsoring Organization Name and Address } \\
\text { Funding was provided by the Office of Naval Research }\end{array}$}} & $\begin{array}{l}\text { 13. Type of Report \& Period Covered } \\
\text { Technical Report }\end{array}$ \\
\hline & & & 14. \\
\hline
\end{tabular}

15. Supplementary Notes

This report should be cited as: Woods Hole Oceanog. Inst. Tech. Rept., WHOI-89-56

16. Abstract (Limit: 200 words)

Data on the effects of winter conditions on the transport of sediment on the continental shelf off Northern California were collected during the first year of the Sediment TRansport Events on Shelf and Slope (STRESS) Experiment. This experiment was done in conjunction with (Shelf MIxed Layer Experiment) SMILE and (Biological Effects on Coastal Ocean Sediment Transport) BECOST to provide a complete suite of measurements of nearshore dynamics, sediment transport, and biological interactions.

This report includes a general description of the work accomplished during the first STRESS field season, carried out in the winter of 1988-1989 off the Northern California coast. Three cruises were completed during the STRESS experiment, one each for deployment, turnaround, and recovery of the instruments. This created two back-to-back sections of data, one from December 4 , 1988 to January 23, 1989, and the other from January 29 to March 17, 1989.

This report also documents in detail the use of the Benthic Acoustic Stress Sensor (BASS), and the associated acoustic data telemetry link in STRESS. BASS has been used in different configurations previously, but the acoustic telemetry system is new.

17. Document Analysis a. Descriptors

1. benthic acoustic stress sensor (BASS)

2. sediment transport

3. radio telemetry

b. Identifiers/Open-Ended Terms

c. COSATI Field/Group

18. Availability Statement

Approved for publication; distribution unlimited.

\begin{tabular}{|l|l|}
\hline $\begin{array}{c}\text { 19. Security Class (This Report) } \\
\text { UNCLASSIFIED }\end{array}$ & $\begin{array}{c}\text { 21. No. of Pages } \\
31\end{array}$ \\
\hline 20. Security Class (This Page) & 22. Price \\
\hline
\end{tabular}

